\title{
A PRODUÇÃO ACADÊMICA SOBRE A QUESTÃO DA VIOLÊNCIA CONTRA A MULHER NA EMERGÊNCIA DA PANDEMIA DA COVID-19 EM DECORRÊNCIA DO ISOLAMENTO SOCIAL
}

\author{
PRODUCCIÓN ACADÉMICA SOBRE LA CUESTIÓN DE LA VIOLENCIA \\ CONTRA LA MUJER EN EL SURGIMIENTO DE LA PANDEMIA COVID-19 \\ COMO RESULTADO DEL AISLAMIENTO SOCIAL
}

\begin{abstract}
ACADEMIC PRODUCTION ON THE ISSUE OF VIOLENCE AGAINST WOMEN IN THE EMERGENCE OF THE COVID-19 PANDEMIC AS A RESULT OF SOCIAL ISOLATION
\end{abstract}

\author{
Solange Aparecida de Souza MONTEIRO ${ }^{1}$ \\ Eduardo YOSHIMOTO ${ }^{2}$ \\ Paulo Rennes Marçal RIBEIRO ${ }^{3}$
}

RESUMO: A pandemia da COVID-19, doença causada pelo novo coronavírus (SARS-CoV2), tem sido amplamente noticiada nas manchetes de jornais e nas redes sociais, por ceifar inúmeras vidas diariamente. Causadora de caos e colapso do sistema de saúde de muitos países, tem sido um dos principais desafios que já resultou em milhares de mortes em todo o mundo e enormes impactos na economia e na educação. O objetivo do presente estudo é realizar uma Revisão Sistemática de Literatura (RSL), a partir de artigos e ensaios científicos sobre os impactos do isolamento social no aumento da violência doméstica contra a mulher, no contexto da pandemia da COVID-19, nesse primeiro semestre de 2020. A pesquisa resultou em 10 artigos e ensaios publicados desde o início do ano de 2020, colhidos na base do Google Acadêmico. Evidencia-se que a pandemia, por meio do isolamento social, apenas visibilizou questões preexistentes como: o aumento da violência contra a mulher, os efeitos da desigualdade social e de direitos entre os gêneros. As mulheres estão ainda mais sobrecarregadas, pois trabalham no cuidado doméstico, no cuidado dos filhos, maridos, companheiros, família e comunidade, sendo também maioria na linha de frente no sistema de saúde. As mais atingidas são mulheres pobres, negras, pardas e com deficiência. Além disso, as pesquisadoras são prejudicadas em relação a sua produção acadêmica.

PALAVRAS-CHAVE: Pandemia. Revisão sistemática de literatura. Isolamento social. Violência doméstica. Violência contra a mulher.

RESUMEN: La pandemia de COVID-19, una enfermedad causada por el nuevo coronavirus (SARS-CoV-2), ha sido ampliamente difundida en los titulares de los periódicos y en las redes

\footnotetext{
${ }^{1}$ Universidade Estadual Paulista (UNESP), Araraquara - SP - Brasil. Pedagoga (IFSP). Doutoranda em Educação Escolar. ORCID: https://orcid.org/0000-0002-1640-0266. E-mail: solmonteiro@ifsp.edu.br

${ }^{2}$ Universidade Estadual Paulista (UNESP), Araraquara - SP - Brasil. Professor da Educação Básica na disciplina de Sociologia na Secretaria da Educação do Estado de São Paulo. Doutorando em Educação Escolar. Pesquisador Bolsista CAPES DS. ORCID: https://orcid.org/0000-0001-6096-677X. E-mail: eduyoshimoto@gmail.com

${ }^{3}$ Universidade Estadual Paulista (UNESP), Araraquara - SP - Brasil. Docente e Coordenador do Programa de Pós-graduação em Educação Sexual. Docente PPG em Educação Escolar. Livre-Docente em Sexologia e Educação Sexual (UNESP). ORCID: https://orcid.org/0000-0002-1552-5702.E-mail: paulorennes@gmail.com
} 
sociales por cobrarse innumerables vidas diariamente. Causando el caos y el colapso del sistema de salud en muchos paises, ha sido uno de los principales desafíos que ha dado lugar a miles de muertes en todo el mundo y a enormes repercusiones en la economía y la educación. El objetivo de este estudio es llevar a cabo una revisión sistemática de la literatura, basada en artículos y ensayos cientificos sobre los efectos del aislamiento social en el aumento de la violencia doméstica contra la mujer, en el contexto de la pandemia de OVID-19, en este primer semestre de 2020. La investigación dio como resultado 10 artículos y ensayos publicados desde principios del año 2020, recopilados en base a Google Academic. Es evidente que la pandemia, debido al aislamiento social, sólo abordó cuestiones preexistentes como: el aumento de la violencia contra la mujer, los efectos de la desigualdad social y los derechos de género. Las mujeres están aún más sobrecargadas, ya que trabajan en el cuidado doméstico, cuidando de los niños, los maridos, las parejas, la familia y la comunidad, y también están en primera línea en el sistema de salud. Las más afectadas son las mujeres pobres, negras, morenas y discapacitadas. Además, los investigadores se ven perjudicados en relación con su producción académica.

PALABRAS CLAVE: Pandemia. Revisión sistemática de la literatura. Aislamiento social. La violencia doméstica. La violencia contra las mujeres.

ABSTRACT: The COVID-19 pandemic, a disease caused by the new coronavirus (SARS-CoV2), has been widely reported in newspaper headlines and on social media, for taking countless lives daily. Causing chaos and the collapse of the health system in many countries, it has been one of the main challenges that has already resulted in thousands of deaths worldwide and huge impacts on the economy and education. The objective of the present study is to carry out a Systematic Literature Review (RSL), based on articles and scientific essays on the impacts of social isolation on the increase in domestic violence against women, in the context of the COVID-19 pandemic, in this first semester of 2020. The research resulted in 10 articles and essays published since the beginning of the year 2020, collected on the basis of Google Scholar. It is evident that the pandemic, through social isolation, only made visible pre-existing issues such as: the increase in violence against women, the effects of social inequality and rights between genders. Women are even more burdened, as they work in domestic care, in the care of children, husbands, partners, family and community, and are also the majority in the front line in the health system. The hardest hit is on the poor, black, brown and disabled women. In addition, female researchers are harmed in relation to their academic production.

KEYWORDS: Pandemic. Systematic literature review. Social isolation. Domestic violence. Violence against women.

\section{Introdução}

Desde a década de 1970, as patologias contagiosas como Herpes, AIDS, Ebola, Síndrome Respiratória Aguda Grave (SARS), Síndrome Respiratória do Oriente Médio (MERS-COV) e, atualmente, a Doença por Coronavírus 2019 (COVID - 19) perturbam e impactam a população mundial. Situações de emergência em saúde já foram vistas anteriormente e a COVID- 19 não é diferente (VALENTIN et al., 2019; ARSHAD et al., 2020; 
JONES, 2020). O atual cenário mundial é de caos na saúde, impactando também os setores econômicos, educacionais e familiar. O novo coronavírus e a COVID-19 têm sido pauta de discussões em todos os âmbitos da sociedade, aprofundando divergências entre cientistas, médicos e a população em geral, especialmente no Brasil, em que o próprio presidente da República desconsidera as recomendações da Organização Mundial de Saúde (OMS), persistindo em um discurso que divide opiniões e população. Em meio à crise, houve a troca de dois ministros na pasta da Saúde e, atualmente, o cargo está vago há mais de um mês, dificultando uma ação coordenada entre os entes federados, tornando o Brasil um dos países mais contaminados e atingidos pela doença.

Esta pesquisa tem cunho bibliográfico e se propõe a fazer uma Revisão Sistemática da Literatura (RSL), expondo especialmente os índices de violência contra a mulher, nesse contexto pandêmico, e outros impactos significativos e ainda não completamente dimensionados sobre a sociedade.

O isolamento social é uma medida de proteção à vida humana, porém tem sido registrado um aumento dos casos de violência doméstica contra as mulheres. Umas das causas apontadas é a maior permanência das mulheres na convivência com os agressores, conforme publicado recentemente pelo Observatório da Mulher contra a Violência (OMV), vinculado à Secretaria de Transparência do Senado, no boletim "Violência doméstica em tempos de Covid19" (BOLETIM-SENADO, 2020). O isolamento social imposto pela pandemia da COVID-19 traz à tona, de forma potencializada, alguns indicadores preocupantes acerca da violência doméstica e familiar contra a mulher.

Por um outro lado, é preciso refletir sobre as contribuições da produção acadêmica, que poderiam, em tese, identificar e contribuir no combate à violência contra a mulher em tempos de pandemia. A nova pandemia de coronavírus é a maior emergência de saúde pública enfrentada pela comunidade internacional em décadas. Além das preocupações relacionadas à saúde física, também traz preocupações relacionadas ao sofrimento psicológico que a população em geral e os profissionais de saúde podem experimentar. Dessa forma, o objetivo do presente estudo foi sistematizar o conhecimento dos impactos psicológicos, sociais e econômicos relacionadas à nova pandemia de coronavírus. São apresentados resultados sobre os impactos da pandemia na saúde mental, identificação de grupos prioritários e orientações sobre intervenções, considerando as particularidades da população em geral e dos profissionais de saúde. 


\section{Pandemia e violência doméstica}

A violência doméstica é um tópico extremamente relevante em tempos de pandemia, antes de tudo, porque a atual situação socioeconômica tende a acentuá-la. Perdas de emprego devido à crise afeta particularmente as mulheres, que se concentram no setor de serviços, que é o mais afetado pela crise. No Brasil, as mulheres estão mais sujeitas à informalidade do que os homens, mais de $90 \%$ dos trabalhadores. A maioria das famílias economicamente vulneráveis na crise são mulheres e mais de $70 \%$ são negras, indicando a maior precariedade de emprego.

Butler (2015 p. 46-47) aponta que a condição precária designa a condição politicamente induzida, na qual certas populações sofrem com redes sociais e econômicas de apoio deficientes e ficam expostas de forma diferenciada às violações, à violência e à morte. Essas populações estão mais expostas a doenças, pobreza, fome, deslocamentos e violência, sem nenhuma proteção. A condição precária caracteriza a condição, politicamente induzida, da precariedade para populações expostas à violência arbitrária do Estado que, com frequência, não tem opção a não ser recorrer ao próprio Estado contra o qual precisam de proteção.

Em relação à violência de gênero, Saffioti $(2002$, p. 2) discute o conceito de forma ampla, abrangendo vítimas como mulheres, crianças e adolescentes de ambos os sexos. No exercício da função patriarcal, os homens detêm o poder de determinar a conduta das categorias sociais nomeadas, recebendo autorização ou, pelo menos, tolerância da sociedade para punir o que se lhes apresenta como desvio. Ainda que não haja nenhuma tentativa, por parte das vítimas potenciais, de trilhar caminhos diversos do prescrito pelas normas sociais, a execução do projeto de dominação/exploração da categoria social homens exige que sua capacidade de mando seja auxiliada pela violência.

A sobrecarga de tarefas domésticas e funções de cuidado também pode prejudicar o desempenho de mulheres que adotaram com sucesso modos remotos de trabalho. Por esse motivo, a situação resultante da pandemia, pode penalizar desproporcionalmente muitas trabalhadoras, causando uma carga maior de mulheres demitidas de seus postos de trabalho. Silva (2012) e Silva e Fonseca Neto, (2014), indicam que, em outra crise econômica, como a ocorrida em 2008 no Brasil, as mulheres eram as que mais sofreram processos demissionários. Portanto, é descrita uma estrutura na qual as mulheres se tornam mais dependentes financeiramente de seus companheiros e é, neste momento de quarentena que as famílias passam o dia todo no mesmo ambiente, em uma coexistência forçada, que pode exacerbar tensões tornando-se um fator que contribui para a violência doméstica. 
Escapar da situação de violência fica ainda mais difícil pela restrição de serviços e movimento em quarentena, devido a uma possível diminuição da renda e devido à ininterrupto e diário com o seu agressor. Esse cenário se reflete em estatísticas de todo o mundo: na China, reclamações de violência doméstica aumentou três vezes no período da pandemia e, na França, as queixas aumentaram 32\% (BIANQUINI 2020). No Brasil, o Ministério da Mulher, Família e Direitos Humanos encontrou um aumento de quase 9\% em denúncias feitas no disque 180, por denúncia de violência doméstica (BINQUINI, 2020). A Justiça do Estado do Rio de Janeiro informou que mais $50 \%$ dos casos foram registrados violência doméstica desde o momento em que o confinamento se tornou inevitável (BERTON, 2020). Silvia Federici (2019) aborda que o trabalho reprodutivo é compreendido como o complexo de atividades e relações por meio das quais nossa vida e nosso trabalho são reconstituídos diariamente (p. 20). De acordo com a jornalista Letycia Bond (2020), a cada quatro minutos é registrado um caso de agressão. Em 2018 foram registrados 145 mil casos de violência - física, psicológica, sexual - em que as vítimas sobreviveram. O Fórum Brasileiro de Segurança Pública (FBSP) a pedido do Banco Mundial, atualizou o relatório onde os casos de feminicídio cresceram $22,2 \%$, entre março e abril de 2020, em 12 estados do país, comparativamente ao ano passado. Intitulado "Violência Doméstica durante a Pandemia de Covid-19”, o documento tem como referência dados coletados nos órgãos de segurança dos estados brasileiros.

\section{Combate à violência doméstica no contexto nacional da pandemia}

No Brasil, as medidas para lidar com esse tipo de violência são mais urgentes, dada a nossa posição sombria nas estatísticas mundiais sobre violência doméstica e feminicídio. $\mathrm{O}$ diretório do feminicídio é responsável por 2,3 mortes por 100.000 mulheres em todo o mundo e 4 mortes por 100.000 mulheres em todo o mundo Brasil (BIANQUINI, 2020). Em outras palavras, nossa taxa é $74 \%$ superior à média mundial. A região da América Latina, em geral, é a mais perigosa para as mulheres fora das zonas de guerra, segundo a ONU (BIANQUINI, 2020). E para cada três vítimas de feminicídio no Brasil, duas foram assassinadas em casa, mesmo com o endurecimento da regra com a lei Maria da Penha - Lei 11.340 / 2006 - e a lei sobre feminicídios - lei 13.104 / 2015 o Estado não pode conter o aumento de violência contra as mulheres. Dessa maneira, na visão de Foucault (1996), os corpos dóceis são disciplinados pelo machismo.

Russell, em 1976, no Tribunal Internacional de Crimes contra as Mulheres, utilizou o termo feminicídio para denominar um crime cometido de forma violenta por homens contra as 
mulheres, pelo fato de serem mulheres, ou seja, um crime contra o gênero feminino. Anos mais tarde, Russell (2006) denominou o feminicídio como assassinato motivado por ódio, desprezo e sentido de propriedade do corpo das mulheres. Lagarde (2006, p. 221), responsável pela introdução do termo "feminicídio" na academia, tem optado em seus estudos por ele por incluir o fator impunidade, em virtude de ausências legais e de políticas do governo, que geram uma convivência insegura para as mulheres, colocando-as em risco e favorecendo o conjunto de crimes praticados por razões de gênero.

De acordo com Lagarde (2006, p. 221), o feminicídio não é apenas uma violência exercida por homens contra mulheres, mas por homens em posição de supremacia social, sexual, jurídica, econômica, política, ideológica e de todo tipo, sobre mulheres em condições de desigualdade, de subordinação, de exploração ou de opressão, e com a particularidade da exclusão. A autora afirma, ainda, que o "[...] Feminicídio se forja na desigualdade estrutural entre homens e mulheres, bem como na dominação dos homens sobre as mulheres, que encontram na violência doméstica, um mecanismo para a reprodução da opressão das mulheres" (LAGARDE, 2006, p. 221). A autora acrescenta ao conceito de Russell o aspecto da impunidade na sociedade e a desigualdade de gênero produzida pelo patriarcado, e tipifica o crime como "crime de Estado". Lagarde complementa, ainda, que o crime se manifesta em todos os momentos, em tempo de guerras ou de paz.

\section{Método}

A presente pesquisa utiliza uma Revisão Sistemática da Literatura (RSL), conforme preconizada por Morandi e Camargo (2015) e sistematizada por Brizola e Fantin (2016), para encontrar artigos científicos relacionados à violência doméstica e de gênero no contexto da pandemia da COVID-19. A busca bibliográfica incluiu trabalhos publicados no início de janeiro até a $1^{\mathrm{a}}$ quinzena de junho de 2020, na base de dados do Google Acadêmico. A escolha dessa base foi feita por reunir, em uma pesquisa única, outras bases de dados de domínio nacional. Foi definido somente um tema, conforme apontam Brizola e Fantin (2016). A definição do tema central exige o entendimento da amplitude da revisão a ser realizada, nesse caso, com um escopo menos extenso, abordando um tema específico: a violência doméstica contra a mulher no contexto da COVID-19. Os descritores e operadores booleanos utilizados foram: "violência” AND “doméstica" AND "gênero" AND “mulher” AND “covid-19” AND “2020”. Essa busca foi realizada de acordo com os critérios de inclusão e exclusão previamente determinados. 
O framework (estrutura) conceitual foi utilizado para determinar critérios de inclusão e exclusão (BRIZOLA; FANTIN, 2016). Os critérios de inclusão utilizados nesta RSL foram: artigos e ensaios científicos publicados em português, artigos e ensaios publicados em revistas ou plataformas científicas, artigos e ensaios publicados de janeiro até a $1^{\text {a }}$ quinzena de junho de 2020, artigos e ensaios completos e artigos e ensaios relacionando os temas: violência doméstica, violência contra a mulher no contexto da pandemia da COVID-19. Os critérios de exclusão utilizados na revisão bibliográfica foram: estudos em que os temas de inclusão definidos não apareceram de forma articulada ou foram secundarizados no artigo, artigos duplicados, artigos não disponíveis para acesso na íntegra, documentos de projetos, cartilhas, artigos de opinião, boletins, notícias, comunicados e notas técnicas.

Análise dos resultados: a partir dos descritores foram gerados 113 resultados. Refinouse a quantidade de artigos considerando os critérios de inclusão e exclusão determinados, fezse uma primeira leitura dos resumos, analisando se eram compatíveis com os temas propostos; chegou-se a 22 artigos. Entretanto, após uma segunda leitura flutuante dos textos, foram descartados 2 artigos completos, pois não contemplavam os objetivos propostos na pesquisa, 10 artigos não tinham o texto integral disponibilizado, somente resumo ou resumo expandido. Chegou-se então a 10 textos, 7 artigos e 3 ensaios. Após uma terceira leitura, foram destacados pontos principais do texto. Posteriormente, foi realizada uma quarta leitura integral dos textos, produzindo um resumo de seus principais pontos, conforme citados no quadro a seguir:

Quadro 1 - Pesquisas e artigos na interface da violência de gênero e pandemia

\begin{tabular}{|c|c|c|c|}
\hline Título & Autor(es) Ano & Objetivo & Resultado \\
\hline $\begin{array}{c}\text { 1. Violência } \\
\text { contra a mulher } \\
\text { e feminicídio no } \\
\text { Brasil - impacto } \\
\text { do isolamento } \\
\text { social pela }\end{array}$ & $\begin{array}{c}\text { OKABAYASHI, } \\
\text { N. Y. T.; } \text { et al. } \\
\text { COVID-19 }\end{array}$ & $\begin{array}{c}\text { Levantamento } \\
\text { bibliográfico do tema } \\
\text { "violência contra a } \\
\text { mulher" estabelecendo } \\
\text { relações entre essa } \\
\text { violência e a } \\
\text { intercorrência da } \\
\text { COVID-19 no Brasil. }\end{array}$ & $\begin{array}{c}\text { As denúncias aumentaram, mas } \\
\text { não se convertem em boletins de } \\
\text { ocorrência. Todos os dados } \\
\text { apontaram aumento do } \\
\text { feminicídio no Brasil. Novas leis } \\
\text { foram implementadas nesse }\end{array}$ \\
$\begin{array}{c}\text { 2. A violência } \\
\text { doméstica } \\
\text { durante a }\end{array}$ & MARANHÃO, & $\begin{array}{c}\text { A partir de um estudo } \\
\text { de caso com }\end{array}$ & $\begin{array}{c}\text { A pesquisa conclui que a } \\
\text { quarentena, no contexto da } \\
\text { investigou-se a } \\
\text { COVID-19: } \\
\text { entre romances, } \\
\text { feminicídios e } \\
\text { prevenção }\end{array}$ \\
\hline
\end{tabular}




\begin{tabular}{|c|c|c|c|}
\hline $\begin{array}{l}\text { 3. Pandemia é } \\
\text { coisa de mulher: } \\
\text { breve ensaio } \\
\text { sobre o } \\
\text { enfrentamento } \\
\text { de uma doença a } \\
\text { partir das vozes } \\
\text { e silenciamentos } \\
\text { femininos } \\
\text { dentro das } \\
\text { casas, hospitais } \\
\text { e na produção } \\
\text { acadêmica } \\
\end{array}$ & $\begin{array}{l}\text { PIMENTA, D. } \\
2020\end{array}$ & $\begin{array}{l}\text { Refletir a partir de um } \\
\text { estudo comparativo da } \\
\text { epidemia do ebola na } \\
\text { África com a } \\
\text { pandemia atual. Fez-se } \\
\text { apontamentos sobre } \\
\text { questões de raça, } \\
\text { gênero e classe social } \\
\text { e o papel das } \\
\text { mulheres, as mais } \\
\text { afetadas durante a } \\
\text { crise, suas vozes e } \\
\text { silenciamentos. }\end{array}$ & $\begin{array}{c}\text { As epidemias e pandemias } \\
\text { afetam muito mais as mulheres } \\
\text { (pretas, periféricas e deficientes), } \\
\text { há uma sobrecarga física e } \\
\text { psicológica, pois elas são } \\
\text { responsáveis pelo cuidado com } \\
\text { doentes, gestão dos recursos } \\
\text { domésticos e tarefas. As } \\
\text { mulheres pesquisadoras também } \\
\text { sentem esses impactos, } \\
\text { diminuindo a pesquisa, } \\
\text { provocando, assim, um outro tipo } \\
\text { de silenciamento. }\end{array}$ \\
\hline $\begin{array}{l}\text { 4. Pandemia de } \\
\text { covid-19 e } \\
\text { gênero uma } \\
\text { análise sob a } \\
\text { perspectiva do } \\
\text { princípio } \\
\text { constitucional } \\
\text { da isonomia }\end{array}$ & $\begin{array}{l}\text { SIQUEIRA, H. } \\
\text { C. B. et al. } \\
2020\end{array}$ & $\begin{array}{l}\text { Demostrar a } \\
\text { contradição entre a } \\
\text { teoria de direitos e a } \\
\text { prática na sociedade } \\
\text { brasileira em relação à } \\
\text { desigualdade de } \\
\text { gênero, sobretudo, no } \\
\text { momento de crise da } \\
\text { pandemia de Covid- } \\
19 .\end{array}$ & $\begin{array}{l}\text { A desigualdade de gênero fica } \\
\text { ainda mais evidenciada nos } \\
\text { momentos de crise, como a atual } \\
\text { pandemia. No discurso jurídico, } \\
\text { existe a igualdade formal entre } \\
\text { mulheres e homens, mas na } \\
\text { prática ela não acontece. O } \\
\text { direito deve ser a ferramenta para } \\
\text { reivindicação da isonomia e } \\
\text { garantia de exclusão de normas } \\
\text { discriminatórias. } \\
\end{array}$ \\
\hline $\begin{array}{c}5 . \\
\text { Interseccionali- } \\
\text { dade e outros } \\
\text { olhares sobre a } \\
\text { violência contra } \\
\text { mulheres em } \\
\text { tempos de } \\
\text { pandemia pela } \\
\text { covid-19 }\end{array}$ & $\begin{array}{l}\text { BARBOSA, J. P. } \\
\text { M; et al. } \\
2020\end{array}$ & $\begin{array}{c}\text { Problematizar o } \\
\text { aumento das } \\
\text { violências domésticas } \\
\text { durante o isolamento } \\
\text { social em tempos de } \\
\text { pandemia. Evidenciar } \\
\text { as relações dinâmicas } \\
\text { que atravessam o } \\
\text { aumento da violência, } \\
\text { a partir do } \\
\text { tensionamento entre } \\
\text { gênero e outras } \\
\text { intersecções. }\end{array}$ & $\begin{array}{c}\text { Pensar territórios de cuidados } \\
\text { para além dos processos saúde- } \\
\text { doença em uma perspectiva da } \\
\text { análise da complexidade: afetos, } \\
\text { empatias, solidariedade, } \\
\text { sororidade, emancipação, } \\
\text { libertação de mulheres e homens } \\
\text { no contexto pandêmico, } \\
\text { denunciando a violência na } \\
\text { sociedade patriarcal brasileira. } \\
\text { Na perspectiva da } \\
\text { interseccionalidade, valoriza-se a } \\
\text { singularidade e a diferença, } \\
\text { entendendo os diversos fluxos } \\
\text { que atravessam as mulheres em } \\
\text { tempo de pandemia. É possível } \\
\text { reformular e arquitetar vias de } \\
\text { inauguração de novas } \\
\text { possibilidades. }\end{array}$ \\
\hline $\begin{array}{l}\text { 6. Governança } \\
\text { econômica } \\
\text { global e } \\
\text { desigualdade de } \\
\text { gênero: uma } \\
\text { agenda para a } \\
\text { pesquisa } \\
\text { jurídica } \\
\text { brasileira no } \\
\text { pós-crise da } \\
\text { COVID-19 }\end{array}$ & $\begin{array}{c}\text { DURAN, C. V. } \\
2020\end{array}$ & $\begin{array}{c}\text { Aborda um tema ainda } \\
\text { pouco explorado pela } \\
\text { pesquisa jurídica } \\
\text { brasileira: a } \\
\text { intersecção entre } \\
\text { direito, governança } \\
\text { econômica global e } \\
\text { igualdade de gênero } \\
\text { tratada por } \\
\text { organizações de } \\
\text { cooperação } \\
\text { econômicas como o } \\
\text { Banco Mundial e o } \\
\text { FMI. }\end{array}$ & $\begin{array}{c}\text { A pandemia aprofunda as } \\
\text { desigualdades já existentes e } \\
\text { expõe a vulnerabilidade social, } \\
\text { jurídica e econômica das } \\
\text { mulheres, ampliada pelo impacto } \\
\text { da crise. A pesquisa jurídica } \\
\text { brasileira tem uma pauta de } \\
\text { gênero urgente a ser } \\
\text { desenvolvida. Construiu-se uma } \\
\text { análise de estudos empíricos e } \\
\text { correntes teóricas em economia } \\
\text { política em combinação com } \\
\text { correntes do institucionalismo } \\
\text { feminista e jurídico, } \\
\text { configurando arcabouço teórico } \\
\text { robusto para a pesquisa jurídica } \\
\text { brasileira. }\end{array}$ \\
\hline
\end{tabular}




\begin{tabular}{|c|c|c|c|}
\hline $\begin{array}{l}\text { 7. Trabalho e } \\
\text { saúde em } \\
\text { tempos de } \\
\text { pandemia pela } \\
\text { covid-19: } \\
\text { cuidado de si e } \\
\text { direito à } \\
\text { autoproteção } \\
\text { das mulheres }\end{array}$ & $\begin{array}{l}\text { SANTOS, G. B. } \\
\text { M.; et al. } \\
2020\end{array}$ & $\begin{array}{c}\text { Análise e } \\
\text { problematização das } \\
\text { políticas de cuidado } \\
\text { trazendo para a cena o } \\
\text { direito à autoproteção } \\
\text { das mulheres, } \\
\text { profissionais de saúde, } \\
\text { durante a pandemia da } \\
\text { COVID-19. }\end{array}$ & $\begin{array}{l}\text { Profissionais da saúde estão na } \\
\text { linha de frente da pandemia, } \\
\text { estão se infectando e precisando } \\
\text { se afastar do trabalho. Em sua } \\
\text { maioria são mulheres, fazendo } \\
\text { emergir a sobrecarga feminina e } \\
\text { uma crise pelas relações do } \\
\text { capitalismo e dominação de } \\
\text { gênero, corroboram para a } \\
\text { naturalização do papel da mulher } \\
\text { no cuidado. A pandemia tornou } \\
\text { evidente a pesada e desigual } \\
\text { responsabilidade pelo trabalho de } \\
\text { cuidado não remunerado } \\
\text { também. O cuidado de si, } \\
\text { foucaultiano, rompe com a } \\
\text { concepção ensinada às mulheres, } \\
\text { com a ideia deturpada que o } \\
\text { cuidado implica a renúncia de si, } \\
\text { para que não aparente egoísmo. } \\
\text { Afirmar a produção do cuidado } \\
\text { de si como criador de valor e } \\
\text { respeito pela vida de todas e } \\
\text { todos, desmistificando o cuidado } \\
\text { para enxergar, a partir da crise do } \\
\text { cuidado, o corpo feminino } \\
\text { mergulhado no campo político. } \\
\end{array}$ \\
\hline $\begin{array}{l}\text { 8. Para ficar em } \\
\text { casa é preciso } \\
\text { ter casa: } \\
\text { desafios para as } \\
\text { mulheres em } \\
\text { situação de rua } \\
\text { em tempos de } \\
\text { pandemia }\end{array}$ & $\begin{array}{c}\text { NUNES, R. A.; } \\
\text { SOUSA, P. C. S. } \\
2020\end{array}$ & $\begin{array}{l}\text { Refletir acerca dos } \\
\text { desafios que } \\
\text { acometem a mulheres } \\
\text { em situação de rua em } \\
\text { meio à pandemia do } \\
\text { COVID 19. No } \\
\text { contexto é trazida a } \\
\text { discussão da pobreza, } \\
\text { desigualdades sociais e } \\
\text { as condições } \\
\text { socioassistenciais } \\
\text { dessa população. }\end{array}$ & $\begin{array}{l}\text { A tomada de decisão para o } \\
\text { enfrentamento da pandemia junto } \\
\text { a mulheres em situação de rua é } \\
\text { uma questão humanitária. Não } \\
\text { existem medidas ou políticas } \\
\text { públicas especiais nesse } \\
\text { momento. É preciso o } \\
\text { conhecimento aprofundado dessa } \\
\text { população, favorecer a } \\
\text { alimentação utilizando } \\
\text { equipamentos públicos, } \\
\text { transferência de renda, facilitação } \\
\text { do cadastro, aumento de vagas } \\
\text { em abrigos, disponibilização de } \\
\text { pias e banheiros químicos para } \\
\text { higiene. As mulheres são mais } \\
\text { atingidas, dependendo de ações } \\
\text { solidárias de pessoas e grupos da } \\
\text { sociedade civil, invés dos } \\
\text { governos. É preciso refletir } \\
\text { políticas públicas junto com a } \\
\text { sociedade que não sejam somente } \\
\text { emergenciais, mas definitivas } \\
\text { para o reconhecimento dessas } \\
\text { pessoas como sujeitos de direitos. }\end{array}$ \\
\hline $\begin{array}{c}9 . \\
\text { Acontecimento } \\
\text { covid-19: e daí? }\end{array}$ & $\begin{array}{c}\text { 2020, SILVA, M. } \\
\text { C.; et al. }\end{array}$ & $\begin{array}{c}\text { Problematizar os } \\
\text { sentidos produzidos } \\
\text { pela pandemia e a } \\
\text { dimensão de uma ética } \\
\text { da responsabilidade } \\
\text { diante do mundo, que } \\
\text { nos convoca a pensar } \\
\text { "o que estamos }\end{array}$ & $\begin{array}{l}\text { Existe a ilusão de que o vírus } \\
\text { mata igualmente, independente } \\
\text { de classe, contudo, há vidas que } \\
\text { importam, vidas precárias e não } \\
\text { vidas. O vírus convocou um olhar } \\
\text { mais apurado das desigualdades e } \\
\text { processos de exclusão. As } \\
\text { mulheres estão no grupo mais }\end{array}$ \\
\hline
\end{tabular}




\begin{tabular}{|c|c|c|c|}
\hline & & $\begin{array}{l}\text { fazendo" do e no } \\
\text { mundo. }\end{array}$ & $\begin{array}{l}\text { afetado pelas consequências da } \\
\text { pandemia, elas estão na colisão } \\
\text { interseccional, negras, pobres, } \\
\text { trabalhadoras informais, vivendo } \\
\text { em condições precárias, sofrendo } \\
\text { violência doméstica. São } \\
\text { cuidadoras e são a maioria na } \\
\text { linha de frente na saúde. }\end{array}$ \\
\hline $\begin{array}{l}\text { 10. Direito à } \\
\text { cidade: } \\
\text { revisitando o } \\
\text { conceito de } \\
\text { Henri Lefebvre } \\
\text { sob uma } \\
\text { perspectiva } \\
\text { marxista } \\
\text { feminista }\end{array}$ & $\begin{array}{l}\text { 2020, GALETTI, } \\
\text { C. C. H.; } \\
\text { DRUMOND, N. }\end{array}$ & $\begin{array}{c}\text { Apoiando-se na obra } \\
\text { de Henri Lefebvre } \\
\text { sobre o "Direito à } \\
\text { Cidade", o trabalho } \\
\text { busca aprofundar o } \\
\text { debate acerca das } \\
\text { relações de gênero e } \\
\text { como elas constituem } \\
\text { as relações de poder } \\
\text { no e a partir do espaço } \\
\text { urbano. }\end{array}$ & $\begin{array}{l}\text { Foi inserido o conceito de divisão } \\
\text { sexual do trabalho no impacto da } \\
\text { conformação da urbanidade na } \\
\text { perspectiva lefebvriana para } \\
\text { identificar o lugar das mulheres } \\
\text { no que define o direito à cidade. } \\
\text { A noção de trabalho reprodutivo } \\
\text { é central nas discussões } \\
\text { relacionadas à procriação, } \\
\text { manutenção e expansão da vida } \\
\text { desempenhadas por mulheres, na } \\
\text { maioria das vezes, não } \\
\text { remuneradas. Essas relações } \\
\text { determinam e são determinadas } \\
\text { por meio da forma como elas } \\
\text { vivenciam a cidade e os conflitos } \\
\text { que surgem a partir daí. O } \\
\text { contato da teoria de Lefebvre } \\
\text { com a teoria feminista possibilita } \\
\text { uma análise das simetrias de } \\
\text { gênero, das contradições de } \\
\text { classe e raça expressadas no } \\
\text { espaço urbano agora no contexto } \\
\text { da pandemia. }\end{array}$ \\
\hline
\end{tabular}

Fonte: organizado pelos autores.

Para Brizola e Fantin (2016), da síntese dos resultados primários selecionados pelos pesquisadores, espera-se que estes gerem um novo conhecimento não existente nos estudos selecionados para a revisão. Assim, torna-se necessário fazer uma relação entre os textos pesquisados, existência de padrões e integração dos dados. Nas revisões qualitativas e nessa, especificamente, optou-se pela triangulação ecológica, na qual entende-se “[...] que as diferentes questões abordadas no estudo são interdependentes e por isso propõem que um fenômeno deve ser estudado sob diferentes pontos de vista" (BRIZOLA; FANTIN, 2016, p. 14).

Observou-se, em todos os artigos analisados algumas regularidades. A primeira é a relação inconteste do aumento da violência doméstica, principalmente relacionada à violência de gênero com o isolamento social, medida estratégica e preventiva adotada em convenção da OMS para a não proliferação do vírus durante a pandemia. A segunda regularidade aponta que o agressor é sempre alguém próximo, companheiro, marido, namorado residente na mesma casa da vítima. Uma terceira regularidade está no fato de que houve a diminuição da rede de proteção, a impossibilidade de contato, devido ao isolamento social, e a paralização de serviços 
por conta da pandemia. Os artigos e ensaios também trouxeram as estatísticas produzidas por instituições e organismos nacionais e internacionais, apontando para o aumento de todos os indicadores da violência doméstica e do feminicídio em diversos países e, principalmente, no Brasil, em estados e capitais. Contudo, é preciso destacar que mesmo antes da pandemia esses números já estavam em crescimento no Brasil.

O perfil das mulheres retratado na maioria dos artigos é bem claro e escancara a desigualdade social e de gênero: pobres, pretas, pardas, das periferias, bairros e favelas, com baixa escolaridade e no trabalho informal. Nesse sentido, a maioria dos artigos e ensaios aponta também para a sobrecarga das tarefas e a dupla jornada, doméstica e do trabalho. Além disso, as mulheres nas epidemias são cuidadoras de seus companheiros, filhos, famílias e comunidade. Elas têm maior risco de contágio e, se adoecerem, serão cuidadas, provavelmente, por outras mulheres. Um dos artigos enfatiza o pós-pandemia e qual o legado que essas mulheres enfrentarão, ou seja, considera-se a perda de direitos, empregos, as crianças nascidas nesse contexto e o acirramento maior das desigualdades.

Nos artigos também apareceram possíveis estratégias e medidas de prevenção e de ação para minimizar a violência doméstica e contra a mulher. Dentre elas destaca-se, o aproveitamento de outras experiências, com outras endemias ou epidemias; aumento da rede de proteção e de capacitação de profissionais da saúde para lidarem com a diversidade; alternativas de canais de comunicação para denúncia como sites, aplicativos, programas de mensagens entre outros; locais alternativos para fazer a denúncia em tempos de pandemias, por exemplo, estabelecimentos de serviços essenciais (supermercados e farmácias, por exemplo).

Em 4 artigos foi abordada a mídia. No segundo artigo, Maranhão (2020) apresenta três casos de violência contra a mulher, no contexto da pandemia, expostos nos noticiários, jornais entre outros. Já no terceiro texto, um ensaio científico, Pimenta (2020) demostra como a mídia construiu uma imagem mundial para a pandemia: "a pandemia com a face das mulheres". No quinto texto, outro ensaio, Barbosa et al. (2020) questionam o papel da mídia em fragmentar o aumento da violência contra mulher numa relação de causalidade com a pandemia, resultando num possível esvaziamento de uma análise histórica e social envolvendo a violência de gênero. Vê-se a mesma hipótese do esvaziamento histórico e social nos casos de outros dois textos, em Maranhão (2020), no segundo artigo, indicando que a mídia tradicional não deixou de reproduzir discursos hegemônicos, naturalizando a violência, mas sem discuti-la; e no segundo caso, no terceiro texto (PIMENTA, 2020), racializou-se o rosto das mulheres na pandemia, insistindo no rosto branco ocidental. Por fim, no nono ensaio, Silva et al. (2020) dizem que a mídia repercute "a invisibilidade" dos que estão no limbo, entre a faixa de vulnerabilidade 
social, atendidos por programas de transferência de renda, e os da classe média-pobre, os autônomos, invisíveis para o Estado. Para Gregolin em uma entrevista dada em 2018, a mídia, numa perspectiva foucaultiana, é o principal dispositivo que agencia e produz subjetividades (DIAS DE OLIVEIRA; OLIVEIRA; NOGUEIRA, 2018).

No campo legal, pontua-se em todos os textos algumas formas de pensar a questão do direito das mulheres, as mulheres como sujeito de direito, seja em acordos e iniciativas internacionais como os Direitos Humanos, ONU Mulheres, ou nacionais, como na Constituição de 1988 e nas leis como a Lei Maria da Penha (Lei n $11.340 / 2006)$ e a Lei do Feminicídio (Lei $\left.n^{\circ} 13.104 / 2015\right)$ e os Projetos de Lei PL 1.796/2020 urgência dos processos, não suspensão dos atos processuais em causas que evolvam violência doméstica ou familiar e a PL 1.798/2020, permitindo que o registro de ocorrência da violência doméstica e familiar contra a mulher possa ser realizado pela internet ou número de telefone de emergência.

O primeiro artigo, Okabayashi et al. (2020), contextualiza historicamente como se deram as lutas e marcos para o desenvolvimento de leis contra a violência sofrida pelas mulheres: nos anos 1970, as conferências realizadas pela ONU; nos anos 1980, no Brasil, um marco importante, a Constituição Federal e a isonomia entre os gêneros; já nos anos 2000, a Lei Maria da Penha; e, finalmente, somente na metade da década de 2010, uma Lei do feminicídio, as autoras apresentam, ainda, dois Projetos de Lei PL 1.796/2020 que coloca urgência em processos de violência doméstica e familiar e o PL 1.798/2020 dando a possibilidade de denúncia pela internet ou telefone desses crimes. Maranhão (2020), no segundo artigo, discorre como essas leis, principalmente as específicas para as mulheres, foram aprovadas tardiamente na América Latina, sendo a primeira delas da Costa Rica em 2007. Ressalta-se o Brasil como último país a ter um a lei específica contra o assassinato de mulheres - Lei $n^{\circ} 13.104 / 2015$, promulgada somente em 2015.

Pimenta (2020), no terceiro texto, um ensaio científico, não trata da questão dos direitos das mulheres do ponto de vista formal, mas ao comparar a sua experiência no campo de estudos com a epidemia de ebola na África e a atual pandemia, coletando relatos daquelas mulheres, reflete sobre o "dever" destas de estar à frente dessa crise nova sendo "a face da pandemia", mas sem ter o direito a voz. No quarto artigo, Siqueira et al. (2020) abordam o princípio constitucional da isonomia na perspectiva do gênero, as autoras afirmam que essa igualdade só existe em teoria, não acontecendo na prática e no cotidiano, assim, percebe-se que a pandemia só deu maior visibilidade a busca desses direitos conquistados e, ao mesmo tempo, negados. Para as autoras, o direito é um instrumento de transformação social, somente se deixar de ser apenas garantidor de direitos, é preciso convertê-los em tutela efetiva das mulheres sobre seus 
direitos e necessidades básicas, as autoras colocam em movimento uma crítica feminista liberal do discurso de isonomia e expõe a falsa compreensão de que as mudanças foram feitas na sociedade, apenas na letra da lei, nesse caso o discurso não se converteu em prática discursiva (FOUCAULT, 1997).

O quinto texto é outro ensaio científico, no qual Barbosa et al. (2020), de outra perspectiva, a da interseccionalidade, abordam as questões de direitos, singularizando-os e criticando modelos homogeneizantes que não consideram a historicização das violências e dos processos, ou seja, destacando o patriarcado como um sistema de dominação. Ainda, no campo dos direitos, Duran (2020), no sexto artigo, propõe discutir a partir do direito e isonomia, combinado com o institucionalismo feminista, a elaboração e ampliação da teoria jurídica nacional no âmbito da governança econômica global; contudo, a base teórica está fundamentada no neoliberalismo, com prescrições externas de instituições e organismos internacionais como Banco Mundial e Fundo Monetário Internacional (FMI). Assim, enfatiza-se o econômico, as mulheres têm papel fundamental na recuperação da economia no pós-pandemia, portanto, a articulação dessa pesquisa jurídica com a linha do institucionalismo feminista é uma vertente do feminismo liberal (RAGO, 2012, p. 71).

No sétimo artigo, Santos et al. (2020), parte do direito à autoproteção das mulheres, do cuidado de si, em termos foucaultianos, do direto à vida e proteção. Para transformar as políticas públicas, as autoras propõem delinear a crise dos cuidados pela qual passamos na atual pandemia. Questionando-se a naturalização dos cuidados como se esses fossem atributos somente do feminino, ao mesmo tempo elas propõem o deslocamento da ética do saber-poder para a possibilidade de outras estéticas da existência, mais justas para mulheres e homens. Mesmo não mencionada diretamente, as autoras trabalham na perspectiva de interseccionalidade.

Nunes e Sousa (2020), no oitavo artigo, não refletem sobre a criação de mais direitos, mas sobre a crise dos direitos constituídos: desrespeito, desmonte, falta, acesso entre outros. Esse fato ocorre, principalmente, com mulheres em condição de rua. A desigualdade e a violência contra as mulheres é uma constante em todos os artigos, e um dos temas elegidos para esta pesquisa é a violência doméstica, então como falar de violência doméstica num artigo sobre mulheres em situação de rua? A resposta é que uma das maiores causas da ida dessas mulheres para a rua é a possibilidade, às vezes a única delas, de rompimento de vínculos com seu agressor. $\mathrm{O}$ artigo discute em alguns momentos, pontualmente, a estrutura da violência em uma sociedade desigual. Não aborda o feminismo, mas toca nas questões da interseccionalidade.

No nono texto, um ensaio científico, Silva et al. (2020), tratam o direito em relação à 
pandemia a partir da ilusão comum: "de que somos todos iguais perante o vírus", suprimindose assim, as desigualdades de base. É interessante o destaque ao "direito à respiração" em Mbembe (2020), onde sujeitos e povos já vinham, antes da pandemia, num processo de sufocamento por meio do extermínio, colonização e objetificação e como o governo atual continua representando a retirada de direitos e a precarização de outros.

O décimo artigo, Galetti e Drumond (2020), falam do direito das mulheres à cidade, numa perspectiva da obra de Lefebvre. É inserida uma crítica feminista em relação ao patriarcado, questiona-se a limitação do conceito desse autor francês de não levar em consideração as questões do gênero. Trata-se da desigualdade de gênero numa perspectiva da experiência urbana das mulheres na mobilidade, nos espaços e na territorialidade.

É preciso colocar em destaque o primeiro (OKABAYASHI et al., 2020), quarto (SIQUEIRA et al., 2020) e sexto (DURAN, 2020) textos, visto que esses têm em comum a questão liberal, mesmo quando abordam o feminismo. Nesses artigos também não houve reflexão sobre o que estrutura as desigualdades de poder entre mulheres e homens na sociedade, dessa maneira, os aspectos culturais foram naturalizados. Entretanto, no quinto (BARBOSA et al., 2020), sétimo (SANTOS et al., 2020), oitavo (NUNES; SOUZA, 2020), nono (SILVA et al., 2020) e décimo (GALETTI; DRUMOND, 2020) artigos, há um outro olhar sobre os direitos, e as discussões dessas autoras, em cada contexto, apontam como questão central a forma da construção e da estruturação da nossa sociedade, portanto, exploram uma perspectiva histórico-social da sexualidade. Enfatiza-se que apenas o segundo texto (MARANHÃO, 2020), dentre todos os analisados, foi escrito por um homem, o autor também traz a questão do patriarcado.

Em todos os artigos fica evidente, nas estatísticas apresentadas, a desigualdade e o aumento da violência de gênero após a aplicação, pelas autoridades, da estratégia do isolamento social. As estatísticas demostram que existem leis para coibirem os crimes, mas não houve diminuição dessa violência, mesmo antes da pandemia. Assim, acredita-se que a ênfase nas desigualdades sociais e, especialmente, nas desigualdades de gênero, simplesmente reproduzem a estrutura histórico-social de nossa sociedade fundada no patriarcado, pois conforme Tiburi (2018), esse enunciado parece estranho, mas reflete o sistema organizado em torno do favorecimento de uns obrigando os outros à submissão. Ainda, segundo a autora, o machismo foi introjetado e se entranhou na macro e microestrutura, na objetividade e na subjetividade, por isso, é reproduzido, inclusive, por muitas mulheres.

Por fim, destaca-se o terceiro ensaio de Pimenta (2020), em que a autora fala da desigualdade existente entre pesquisadores e pesquisadoras. Mesmo dentro da academia e nas 
universidades esse fato se reproduz, porque é um discurso existente na cultura, logo, atravessa todas as instituições. Existe a interdição da mulher, da sua visibilidade e de sua voz. É proposto em alguns artigos, como estratégia de ação, consultar as líderes comunitárias e as meninas e as mulheres das localidades, dessa forma é possível construir políticas públicas envolvendo toda a sociedade, mas dando voz e protagonismo, especialmente, a quem sente essa dura realidade em seus corpos.

\section{Considerações finais}

Os trabalhos analisados tornaram evidentes, com estatísticas de vários órgãos e organizações nacionais e internacionais, que a violência contra as mulheres é generalizada e, no período anterior a pandemia da COVID-19, já vinha numa tendência de aumento. Mais agravante é que, na maioria das vezes, o agressor convive com a vítima, impedindo a denúncia, por esse fato esses casos são sempre subnotificados. Nesse sentido, mesmo com a utilização das ferramentas do direito, sobretudo, leis contra a violência doméstica e, mais duras, como as leis do feminicídio, essas não conseguem inibir e muito menos conter a tendência de aumento desses crimes. Esse trabalho de pesquisa e a produção científica são fundamentais para descrever, identificar, planejar e realizar ações. É importante reconhecer que algumas iniciativas estão sendo realizadas pelo poder público, como dois Projetos de Lei um para não travar processos de violência doméstica nesse período de pandemia e outro que facilita a denúncia e o registro por canais como a internet e telefones por causa do isolamento social. Nesses trabalhos foram propostos uma gama de possibilidades de ampliação da rede de proteção para as mulheres com algumas experiências de outras endemias e epidemias e ações realizadas por outros países.

A questão da interseccionalidade também atravessou todos os trabalhos, mesmo que esses não a abordassem, pois na pandemia as mulheres são as mais atingidas, contudo, há, para muitas delas, a sobreposição dessa desigualdade quando são pobres, pretas ou pardas e deficientes. Elas têm empregos precários, informais, sobrecarga da dupla jornada no trabalho, em casa. Além disso, são as que cuidam de todas e todos, nos cuidados dos parceiros, maridos, namorados, filhos, pais, família e comunidade. Estão na linha de frente da pandemia, pois são a maioria dos profissionais da saúde. Portanto, mais expostas à doença e às condições precárias e de vulnerabilidade. Contudo, a condição dos cuidados relegados exclusivamente para as mulheres é uma questão que vai além do que as ferramentas jurídicas possam equalizar. Essas condições estão estruturadas na forma como se enxergam os sujeitos, as mulheres e homens 
dentro de uma sociedade patriarcal e machista como a brasileira. Os modos de ser e estar e a visão de mundo das pessoas não são rompidas simplesmente com leis instituídas em momentos de crise. Mulheres são mortas pelo fato de serem mulheres e essa quarentena potencializou esses afetos. Toda essa crise aprofundada pelo contexto de um governo com um discurso de base autoritário, misógino e sexista, agora banalizando as mortes e a gravidade da doença.

Medidas voltadas para a diminuição dos efeitos da desigualdade e da exclusão e, sobretudo, para o empoderamento das mulheres com políticas públicas dependem da formação de uma consciência e de uma autocrítica das relações de poder rompendo com as lógicas patriarcais. Assim, a pandemia da COVID-19 somente evidenciou, por meio do isolamento social, um cenário de questões pré-existentes que vinham num continuum, do aumento das estatísticas da violência doméstica contra a mulher, sobrecarga de jornada e trabalho informal. Contudo, para além, dessa realidade os trabalhos também mostraram que existem as resistências e outras possibilidades de ser e de estar no mundo. Pode-se pensar os territórios de cuidados para além dos processos saúde-doença, inserindo uma perspectiva dos afetos empatias, solidariedade, sororidade e emancipação/libertação de mulheres e homens no contexto pandêmico, escapando de protocolos cristalizados. Questiona-se além dessa estrutura patriarcal o sistema capitalista que atomiza, individualiza e privatiza o sofrimento das mulheres, espraiando-se nas instituições e no Estado.

Acentuamos a necessidade de romper também a interdição das vozes das mulheres, tanto na academia, visto que a profusão de textos produzidos por homens nessa pandemia supera a das mulheres e as várias cientistas sociais da região nordeste do Brasil, com pesquisas em endemias e epidemias como zika vírus, dengue, malária, não tem destaque e não aparecem, quanto na sociedade, pois é preciso escutar as vozes das mulheres nas casas e comunidades para desenvolver estudos e a partir desses desenhar políticas públicas mais justas. Ainda que, o objetivo desse trabalho tenha sido alcançado, identificando, por meio da RSL as principais causas de violência doméstica e contra a mulher agravados no contexto da atual pandemia, a partir dessas considerações, novas pesquisas podem ser feitas, pensando-se nas possibilidades de resistência à cultura patriarcal e machista, explorando-se o papel da educação, principalmente, de uma educação sexual sistematizada na academia e no ensino básico e do papel do discurso midiático na reprodução dessa estrutura. 


\section{REFERÊNCIAS}

APES. Não estamos no mesmo barco. Seção Sindical da ANDES - SN, abr. 2020.

Disponível em: https:/www.apesjf.org.br/nao-estamos-no-mesmo-barco-em-entrevistamariana-cassab-fala-sobre-isolamento-social-genero-e-desigualdade. Acesso em: 13 abr. 2020.

ASSOCIAÇÃO NACIONAL DOS DIRIGENTES DAS INSTITUIÇÕES FEDERAIS DE ENSINO SUPERIOR (ANDIFES). ANDIFES - Carta de Vitória, jul. 2019. Disponível em: http://www.andifes.org.br/andifes-carta-de-vitoria/. Acesso em: 1 maio 2020.

BERTON, E. França colocará vítimas de violência doméstica em hotéis. Agência Brasil, 30 mar. 2020. Disponível em: https://agenciabrasil.ebc.com.br/saude/noticia/2020-03/francacolocara-vitimas-de-violencia-domestica-em-hoteis. Acesso em: 22 jun. 2020.

BIANQUINI. H. Combate à violência doméstica em tempos de pandemia: o papel do Direito. Consultor Jurídico, 24 abr. 2020. Disponível em: https://www.conjur.com.br/2020-abr24/direito-pos-graduacao-combate-violencia-domestica-tempos-pandemia. Acesso em 22/06/2020.

BRASIL. Boletim-Senado. Mulheres e seus Temas Emergentes. Violência doméstica em tempos de COVID-19, abr. 2020. Disponível em:

https://www12.senado.leg.br/institucional/omv/pdfs/violencia-domestica-em-tempos-decovid-19. Acesso em: 22 jun. 2020.

BRIZOLA, J.; FANTIN, N. Revisão da literatura e revisão sistemática da literatura. Revista de Educação do Vale do Arinos, v. 3, n. 2, 2016. Disponível em:

https://periodicos.unemat.br/index.php/relva/article/view/1738/1630. Acesso em: 19 jun. 2020.

BUTLER, J. Quadros de guerra: quando a vida é passível de luto? Rio de Janeiro: Civilização Brasileira, 2015.

BUTLER, J. Corpos que importam: os limites discursivos do sexo. São Paulo: Crocodilo, 2019.

FOUCAULT, M. Arqueologia do saber. Rio de Janeiro: Forense Universitária, 2000.

FOUCAULT, M. Resumo dos cursos do Collège de France (1970-1982). Rio de Janeiro: Jorge Zahar, 1997.

GALETTI, C. C. H. Falta de pão e violência doméstica em tempos de coronavírus. Revista Espaço Acadêmico, Marigá, Ano XVIII, 2020. Disponível em:

https://espacoacademico.wordpress.com/2020/04/03/falta-de-pao-e-violencia-domestica-emtempos-de-coronavirus/. Acesso em: 16 jun. 2020.

ONU. ONU MULHERES BRASIL. Gênero e COVID-19 na América Latina e no Caribe Dimensões de gênero na resposta. Disponível em: http:/www.onumulheres.org.br/wpcontent/uploads/2020/03/ONU-MULHERES-COVID19_LAC.pdf. Acesso em: 12 jun. 2020. LAGARDE, M. Del femicidio al feminicidio. Desde el jardín de Freud. Bogotá: n. 6, p. 216- 
225, 2006.

LAGARDE, M.; RUSSELL, D.; HAMES, H. (Orgs.). Feminicidio: una perspectiva global, México, Comisión Especial para Conocer y Dar Seguimiento a las Investigaciones Relacionadas con los Feminicidios en la República Mexicana y a la Procuración de Justicia. Vinculada, 2006.

LETÍCIA, B. Casos de feminicídio crescem 22\% em 12 estados durante pandemia. Agência Brasil, 01 jun. 2020. Disponível em: https://agenciabrasil.ebc.com.br/direitoshumanos/noticia/2020-06/casos-de-feminicidio-crescem-22-em-12-estados-durantepandemia. Acesso em: 23 jun. 2020.

MARANHÃO, R. A. A violência doméstica durante a quarentena da COVID-19: entre romances, feminicídios e prevenção. Brazilian Journal of health Review, v. 3, n. 2, 2020. Disponível em:

http://www.brazilianjournals.com/index.php/BJHR/article/view/8879/7601.Acesso em: 16 jun. 2020.

MBEMBE, A. O direito universal à respiração. Trad. Ana Luiza Braga. n-1 edições - Textos. 2020. Disponível em: https://n-1edicoes.org/textos-1. Acesso em: 16 jun. 2020.

MORANDI, M. I. W. M.; CAMARGO, L. F. R. Revisão sistemática da literatura. In: DRESCH, A.; LACERDA, D. P.; ANTUNES JR, J. A. V. (Orgs.). Design sciencie research: método e pesquisa para avanço da ciência e da tecnologia. Porto Alegre: Bookman, 2015.

NUNES, N. R. A.; SOUSA, P. C. S. Para ficar em casa é preciso ter casa: desafios para as mulheres em situação de rua em tempos de pandemia. Revista Augustus, Rio de Janeiro, v. 25, n. 51, 2020. Disponível em:

https://revistas.unisuam.edu.br/index.php/revistaaugustus/article/view/545/292. Acesso em: 16 jun. 2020.

OKABAYASHI, N. Y. T.; TASSARA, I. G.; CASACA, M. C. G.; FALCÃO, A. A.; BELLINI, M. Z. Violência contra a mulher e feminicídio no Brasil - impacto do isolamento social pela COVID-19. Brazilian Journal of Health Review, v. 3, n. 3, 2020. Disponível em: http://www.brazilianjournals.com/index.php/BJHR/article/view/9998/8381.Acesso em: 16 jun. 2020.

PIMENTA, D. Pandemia é coisa de mulher: breve ensaio sobre o enfrentamento de uma doença a partir das vozes e silenciamentos femininos dentro das casas, hospitais e na produção acadêmica. Tessituras - Revista de Antropologia e Arqueologia, Pelotas, v. 8, 2020. Disponível em:

https://periodicos.ufpel.edu.br/ojs2/index.php/tessituras/article/view/18900/11446.Acesso em: 16 jun. 2020.

RAGO, M. Mujeres Libres: anarco-feminismo e subjetividade na Revolução Espanhola. Verve. Revista do Núcleo de Sociabilidade Libertária, São Paulo, v. 7, p. 132-152, 2005.

RUSSELL, D. E. H.; VAN DE VEN, N. Violência de gênero no Brasil atual. Revista Estudos Feministas, n. esp., p. 443-461, 1994. 
RUSSELL, D. E. H.; VAN DE VEN, N. Crimes against women: the proceedings of the international tribunal, San Francisco, California, frog in the well, 1982. In: SAFFIOTI, H. Contribuições feministas para o estudo da violência de gênero. Cadernos Pagu, n. 16, p. 115136, 2001.

SANTOS, G. B. M.; LIMA, R. C. D.; BARBOSA, J. P. M.; SILVA, M. C.; ANDRADE, M. A. C. Trabalho e saúde em tempos de pandemia pela covid-19: cuidado de si e direito à autoproteção das mulheres. Disponível em:

https://preprints.scielo.org/index.php/scielo/preprint/view/528/669. Acesso em: 16 jun. 2020.

SILVA, F. J. F. Perfil dos demitidos durante a crise de 2008 no Brasil. In: ENCONTRO NACIONAL DE ESTUDOS POPULACIONAIS: TRANSFORMAÇÕES NA POPULAÇÃO BRASILEIRA: COMPLEXIDADES, INCERTEZAS E PERSPECTIVAS, 2012, Águas de Lindóia. Anais [...]. Águas de Lindóia: ABEP, 2012.

SILVA, F. J. F.; FONSECA NETO, F. A. Efeitos da crise financeira de 2008 sobre o desemprego nas regiões metropolitanas brasileiras. Nova Econ., Belo Horizonte, v. 24, n. 2, 2014.

SILVA, M. C.; SILVA, K.; SIQUEIRA, L. A. R.; ANDRADE, M. A. C. Acontecimento covid-19: e daí? Disponível em: https://preprints.scielo.org/index.php/scielo/preprint/view/520/657. Acesso em 16 jun. 2020.

\section{Como referenciar este artigo}

MONTEIRO, S. A. de S.; YOSHIMOTO, E.; RIBEIRO, P. R. M. A produção acadêmica sobre a questão da violência contra a mulher na emergência da pandemia da COVID-19 em decorrência do isolamento social. Doxa: Rev. Bras. Psico. e Educ., Araraquara, v. 22, n. 1, p. 152-170, jan./jun., 2020. e-ISSN: 2594-8385. DOI: https://doi.org/10.30715/doxa.v22i1.13976

Submetido em: 06/01/2020

Aprovado em: 20/04/2020

Aceito em: 25/05/2020

Publicado em: 01/06/2020 